\title{
Characteristics of Pore Structures and Surface Chemistry of Activated Carbons by Physisorption, Ftir And Boehm Methods
}

\author{
A. Allwar \\ Department of chemistry, Mathematic and Sciences Faculty, Islamic University of Indonesia, Yogyakarta \\ 55584, Indonesia.
}

\begin{abstract}
Highly-porous structures of activated carbon were prepared from oil palm shell. Their adsorptive characteristics and surface chemistry were investigated. Five series of activated carbons were obtained at different temperatures using chemical activation with potassium hydroxide. The results show that the activated carbon produced from $500-700^{\circ} \mathrm{C}$ exhibit Type I isotherm, characteristics of microporous structure. The activated carbon prepared from $800-900^{\circ} \mathrm{C}$ show a combination Type I and IV isotherm with wide hysteresis loop indicating mesoporous structures. The BET surface area and total pore volume increased almost linearly with increasing activation temperatures resulting $2301 \mathrm{~m}^{2} \mathrm{~g}^{-1}$ and $0.55 \mathrm{~cm}^{3} \mathrm{~g}^{-1}$, respectively. Modification of surface chemistry of the activated carbon using chemical treatment with nitrit acid have increased the number of total acid groups. Reaction between nitric acid and activated carbons sharply increased the total acid groups containing of carboxylic, lactonic and phenolic groups as oxygen-surface functional groups. Reaction urea and ammonia with activated carbon provided a numbers of the total basic groups as $\mathrm{N}-\mathrm{H}$ and $\mathrm{NH}_{2}$ groups, indicating the presences of nitrogen-surface functional groups.
\end{abstract}

Key words: Activated carbon, micro- and mesoporous structures, Oxygen and nitrogen-surface functional groups

\section{Introduction}

Well-known porous materials called activated carbons have wide range of properties and physical forms making them to be prominently used in many applications. They are extensively used in variety of industrial and environmental applications [1-3]. The important properties such as surface area, pore volume and pore size distribution are among of which they are strongly associated to the adsorption capacity [4]. Large surface area and high pore volume are widely used in chemical and gas separation, medicine and catalyst while total surface area may supports the accessibility of active site relating to the catalytic activity [5]. Pore size distribution with the combinations of the micropores (pore diameter $<2 \mathrm{~nm}$ ) and mesopores (pore diameter $2-$ $50 \mathrm{~nm}$ ) are required to improve the transport process of particles or molecules inside porous networks and facilitate the adsorption of larger molecules [6].

The presences of heteroatoms on the external surface of porous activated carbon mainly contain oxygen, nitrogen, halogen, hydrogen, etc which are chemically bonded to the edges of carbon layers and governed to the surface functional groups [7]. Surface chemistry on the porous materials has a considerable effect on their reactivity including catalytic, electrical and reactivity of the porous materials, and surface characterizations such as wettability, polarity and acidicity. Many researchers are investigating as how to modify as well as to characterize the surface functional groups in order to improve or extend their practical applications [8]. The presence of heteroatoms on the surface plays an important role on its application. Previous studies reported that some modification of surface functional groups can be conducted by thermal and chemical methods [9]. Surface functional groups containing oxygen and nitrogen may increase free valences on the edges on the external surface as they are very reactive [10]. The oxygen and nitrogen functional groups may act to form coordination chemistry in attracting heavy metals in aqueous and non-aqueous solutions for treatment of waste and toxic effluences $[4,11]$.

Due to their excellent characteristics, activated carbons have increasingly been used in numerous practical applications [12]. Consequently, the world consumption of activated carbon have steadily increased and also not been replaced until now, despite hard competitions from zeolytes, polymer and other newadsorbents. This can be seen from the constant increased in number of publications over the years. Recently, considerable efforts have also been increasingly directed to the comprehensive understanding of porous activated carbon in taking advantage of the agricultural byproduct and also on improvement of product performance as well as surface functional groups [13].

Activated carbons can be prepared from variety of byproduct solid wastes as the raw materials which consist of carbon-rich materials. However, a well-developed porous structure of the carbon depends not only on the type of raw materials but also on the appropriate methods used to prepare it. Basically, there are two methods for preparation of activated carbon which are physical and chemical activation processes. In physical 
process, the raw material such as wood, shell, etc. is carbonized or pyrolyzed in the absence of air and any chemicals which usually produce a rudimentary char or poor porous structures. This is further followed by the activation process in order to improve its porous structure [14]. In chemical process, raw material is impregnated by chemical activating agents such as phosphoric acid, potassium hydroxide, sodium carbonate, sodium hydroxide, potassium carbonate, phosphoric acid, zinc chloride, etc [15]. The impregnated sample is then activated under nitrogen, carbon dioxide or steam. Activation is a very important process in order to initiate the formation of pores. The process usually involves cleaning out of tars-clogging, forming of new pores and finally, enlarging the surface areas. Preparation of the activated carbon with chemical activation is sometimes preferred due to some advantages in their properties such as high surface area, adequate pore volume and variety of pore size distributions $[11,16]$.

In this study, highly-porous structure of activated carbon was prepared from oil palm shell, by-product oil palm industry by chemical activation with $\mathrm{KOH}$ solution. The physical characteristics were measured from nitrogen adsorption-desorption isotherms at $77 \mathrm{~K}$ data using the Brunauer, Emmett and Teller (BET), Langmuir isotherm, t-plot, and Dubinin-Radushkevich (D-R) methods. The morphology structure and elemental microanalysis of the carbons were observed by the scanning electron microscope (SEM) and the energy dispersive Xray analysis (EDX), respectively. Surface chemistry was carried out by FTIR and Boehm titration method.

\subsection{Raw material characteristics}

\section{EXPERIMENTAL}

In this experiment performed, sample of oil palm shell originating from byproduct of oil palm industry. Thermogravimetric Analyzer (model TGA 7, Perkin Elmer) and Elemental Analyzer (model Series II, 2400, Perkin Elmer) was used to investigate raw materials and activated carbons. Table 1 presents the characteristics of raw material and activated carbons on dry basis. The Oxygen $(\mathrm{O})$ content was measured on wt $\%$ basis after elimination of carbon $(\mathrm{C})$, hydrogen $(\mathrm{H})$ and nitrogen $(\mathrm{N})$ contents.

Table 1: Proximate and elemental analysis of oil palm shell (OPS) and activated carbon (AC)

\begin{tabular}{|c|c|c|c|c|c|c|c|c|c|}
\hline \multirow{2}{*}{\multicolumn{2}{|c|}{ Samples }} & \multicolumn{4}{|c|}{ Proximate analysis (\%) } & \multicolumn{4}{|c|}{ Elemental analysis (\%) } \\
\hline & & Moisture & $\begin{array}{l}\text { Volatile } \\
\text { matter }\end{array}$ & $\begin{array}{c}\text { Fix } \\
\text { carbon }\end{array}$ & Ash & $\mathrm{C}$ & $\mathrm{H}$ & $\mathrm{N}$ & $\mathrm{O}$ \\
\hline \multicolumn{2}{|c|}{ OPS } & 6.7 & 64.7 & 26.4 & 2.2 & 50.3 & 5.6 & 0.3 & 43.8 \\
\hline \multirow[t]{2}{*}{$\mathrm{AC}$} & $500^{\circ} \mathrm{C}$ & 4.2 & 19.3 & 76.5 & - & 65.1 & 2.5 & 0.4 & 32.0 \\
\hline & $700^{\circ} \mathrm{C}$ & 3.3 & 14.5 & 82.2 & - & 85.4 & 0.6 & 0.4 & 13.6 \\
\hline
\end{tabular}

\subsection{Preparation activated carbon}

Activated carbon was prepared from oil palm shell, byproduct of oil palm industry. Sample was grounded to a particle size $0.5-1.5 \mathrm{~mm}$. It was refluxed into $85 \% \mathrm{KOH}$ solution with ratio $1: 2$ at $85^{\circ} \mathrm{C}$ for $24 \mathrm{~h}$. The mixture was washed with hot water, neutralized with $2 \mathrm{M} \mathrm{HCl}$ and dried into oven at $120^{\circ} \mathrm{C}$. The dried sample was carbonized at different activation temperatures $\left(500-900^{\circ} \mathrm{C}\right)$ under nitrogen with contact time $3 \mathrm{~h}$. The resulting activated carbon was re-carbonized with the previous condition using carbon dioxide instead of nitrogen with contact time $1.5 \mathrm{~h}$. Schematic diagram of the carbonization process was shown from previous research [17].

\subsection{Chemical treatment of Surface Chemistry}

Activated carbon with the highest porous structure performance was used as references for studying its surface functional groups. Approximately, $20 \mathrm{~g}$ each of the reference sample was refluxed in $50 \mathrm{ml}$ of $25 \%$ ammonia, $10 \mathrm{M}$ nitric acid or $50 \%$ urea solution at $65^{\circ} \mathrm{C}$ in a water bath for 24 hours. Thereafter, the mixture was filtered, washed with hot distilled water and dried in oven at $110^{\circ} \mathrm{C}$ for 24 hours. The dried sample was loaded into stainless steel reactor, and set up into the graphite furnace. Activation procedure was carried out under nitrogen purified nitrogen at $400^{\circ} \mathrm{C}$ for $1 \mathrm{~h}$ as contact time.

\subsection{Physical Characterizations of Activated Carbon}

Physical characterizations such as surface area and porous structures of the activated carbon were carried out using nitrogen adsorption-desorption isotherm at liquid nitrogen $77 \mathrm{~K}$. Analysis was conducted by Quantachrome Nova 2200e. Prior analysis carbon samples were degassed at $150^{\circ} \mathrm{C}$ for $8 \mathrm{~h}$. Surface area was determined by application of the BET method at relative pressure in the range of 0.03-0.5 and Langmuir surface area method at relative pressure $<0.05[18]$. Both methods have correlation coefficient $r^{2}>0.999$. External surface area, micropore area and micropore volume was determined by the application of t-plot method, and Total pore volume was carried out at relative pressure at 0.99 . 


\subsection{Characterizations of Surface Functional Groups}

Characterizations of surface functional groups were carried out by FTIR and Boehm titration methods [19].

\subsection{The nitrogen adsorption-desorption isotherm}

\section{Result And Discussion}

Fig. 1 illustrates the nitrogen adsorption-desorption isotherms at $77 \mathrm{~K}$ on the activated carbon generated at different activation temperatures. The three nitrogen adsorption-desorption isotherms at 500 to $700^{\circ} \mathrm{C}$ show similar shapes. The shaped sharply increase at low relative pressure and tend to plateau in the long of relative pressure. These shapes clearly indicate the Type I isotherms, characteristic of microporous materials. On the other hand, when the temperatures activation increased to 800 and $900^{\circ} \mathrm{C}$, the shapes of the nitrogen isotherms continually increase to the end of relative pressure. They are supposed to exhibit a combination of the Type I and IV isotherms, characteristic of the co-existences of microporous and mesoporous materials. The presences of hysteresis loop of type $\mathrm{H} 4$ at relative pressure $>0.4$ proved the formation of slit-like pores associated with the capillary condensation in a well developed mesoporous materials[20]. The evolution of pores from micro- to mesopore could be caused by the presences of $\mathrm{CO}_{2}$ molecules as a gasifying agent, and they were more active to enlarge pores at higher temperatures.

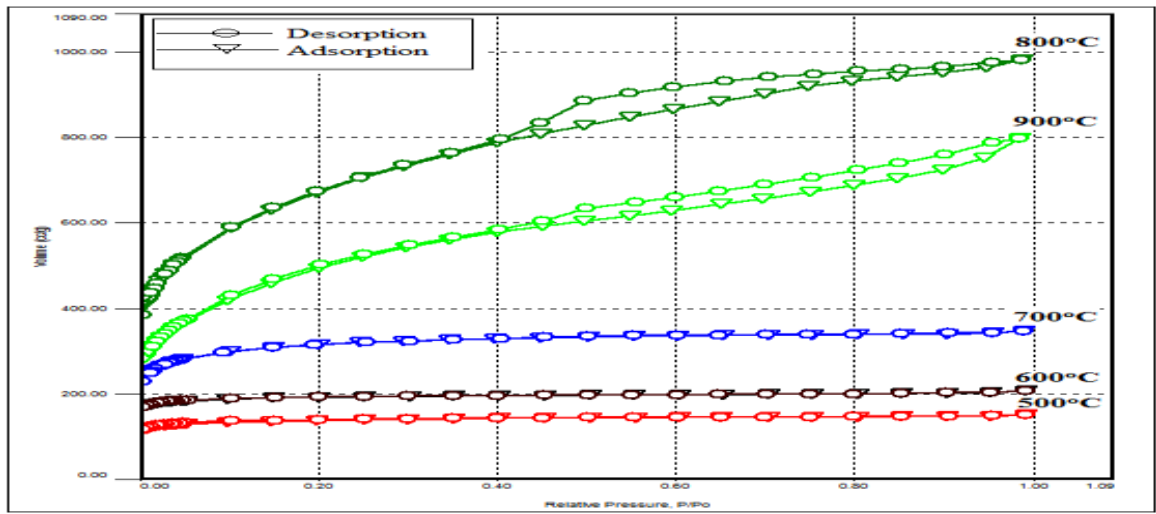

Fig. 1. Nitrogen adsorption-desorption isotherms at $77 \mathrm{~K}$

\subsection{Characteristics of Porosity and Surface Area.}

The determinations of surface area activated carbon were calculated from the nitrogen adsorptiondesorption isotherm data. Langmuir isotherm method was carried out to study the surface area that have Type I isotherm, characteristics micropores. The data of Langmuir plot was obtained at very low relative pressure ranging from 0.001 to 0.05 with a correlation coefficient $r^{2}>0.999$. The BET surface area method was measured for the combination Type I and IV isotherms with wide hysteresis loops which are clearly indicated the extent of pore formation, mainly mesopores. The BET plot was indentified at relative pressure ranging from 0.05 to 0.3 with a correlation coefficient $r^{2}>0.999$.

The differences of nitrogen isotherm shapes might be caused by the effect of carbon dioxide as gasifying agent during the carbonization process. At a low temperature, the molecular gas of carbon dioxide was less active to initiate the formation of porosity. However, at higher temperatures, the molecule was more active and traveled to create or build a new porosity. It was proved that surface area increased linearly with increasing temperature to $800^{\circ} \mathrm{C}$. The result shows that the maximum surface area was $2301 \mathrm{~m}^{2} / \mathrm{g}$. It illustrates that the carbon dioxide molecules played an important role for developing pore structures. However, at temperature $900^{\circ} \mathrm{C}$, the surface area sharply decreased to $1707 \mathrm{~m}^{2} / \mathrm{g}$. It might be caused by the overheating during carbonization process and followed by closing of the porosity or destroying of the porous wall.

Comparison of results from series of activated carbons at different temperatures is shown in Table 2 and 3. The micropore volume and micropore area of activated carbon with Type I isotherm (Table 1) were calculated by The Dubinin-Radushkevich (D-R) method. The total pore volume was determined at relative pressure at 0.99 . The results shown that the micropore volume, micropore area and total pore volume increase with increasing temperatures. It assumed there was an enlargement of porosity. In general, the extent of porous formation continued linearly with increasing temperature to $800^{\circ} \mathrm{C}$ exhibiting Type I and IV isotherm with wide hysteresis loop. The t-plot method was carried out to determine micropore volume, micropore area and external surface area. The results show that maximum values of porous structures were shown by a highly surface area and largely micropore which were obtained at $800^{\circ} \mathrm{C}$. 
Characteristics Of Pore Structures And Surface Chemistry Of Activated

Table 2. Pore stucture of the microporous activated carbons

\begin{tabular}{|c|c|c|c|c|}
\hline \multirow{2}{*}{$\begin{array}{c}\text { Temp. } \\
\left({ }^{\circ} \mathrm{C}\right)\end{array}$} & \multirow{2}{*}{$\begin{array}{l}\text { Langmuir } \\
\text { Surface area } \\
\quad\left(\mathrm{m}^{2} \mathrm{~g}^{-1}\right)\end{array}$} & \multicolumn{2}{|c|}{ Dubinin-Radushkevich } & \multirow{2}{*}{$\begin{array}{l}\text { Total pore volume } \\
\qquad(\mathrm{p} / \mathrm{po}=0.99) \\
\left(\mathrm{cm}^{3} \mathrm{~g}^{-1}\right)\end{array}$} \\
\hline & & $\begin{array}{l}\text { Micropore volume } \\
\qquad\left(\mathrm{cm}^{3} \mathrm{~g}^{-1}\right)\end{array}$ & $\begin{array}{l}\text { Micropore area } \\
\left(\mathrm{m}^{2} \mathrm{~g}^{-1}\right)\end{array}$ & \\
\hline 500 & 582 & 0.22 & 610 & 0.24 \\
\hline 600 & 822 & 0.30 & 845 & 0.32 \\
\hline 700 & 1295 & 0.49 & 1371 & 0.54 \\
\hline
\end{tabular}

Table 3. Pore structure of the mesoporous activated carbons

\begin{tabular}{|c|c|c|c|c|c|c|}
\hline $\begin{array}{c}\text { Temp } \\
\left({ }^{\circ} \mathrm{C}\right)\end{array}$ & $\begin{array}{c}\text { BET } \\
\text { surface } \\
\text { area } \\
\left(\mathrm{m}^{2} \mathrm{~g}^{-1}\right)\end{array}$ & $\begin{array}{c}\text { Micropore } \\
\text { volume } \\
\left(\mathrm{cm}^{3} \mathrm{~g}^{-1}\right)\end{array}$ & $\begin{array}{c}\text { Micropore } \\
\text { area }\left(\mathrm{m}^{2} \mathrm{~g}^{-}\right.\end{array}$ & $\begin{array}{c}\text { External } \\
\text { surface area } \\
\left(\mathrm{m}^{2} \mathrm{~g}^{-1}\right)\end{array}$ & $\begin{array}{c}\text { Total pore } \\
\text { volume } \\
(\mathrm{p} / \mathrm{po}=0.99) \\
\left(\mathrm{cm}^{3} \mathrm{~g}^{-1}\right)\end{array}$ & $\begin{array}{c}\text { Mesopore } \\
\text { Volume } \\
\left(\mathrm{cm}^{3} \mathrm{~g}^{-1}\right)\end{array}$ \\
\hline 800 & 2301 & 0.55 & 1138 & 1163 & 1.52 & 0.97 \\
900 & 1707 & 0.54 & 1098 & 617 & 1.24 & 0.70 \\
\hline
\end{tabular}

\subsection{Characteristics of Surface Functional Groups by FTIR}

\subsubsection{The activated carbon prepared at different temperatures}

Fig. 2 shows the effect of temperatures on the surface functional groups of activated carbons. A band at $3403 \mathrm{~cm}^{-1}$ is assigned to $\mathrm{O}-\mathrm{H}$ stretching vibration in hydroxyl groups. A weak band at $1691 \mathrm{~cm}^{-1}$ observed at temperature of $500^{\circ} \mathrm{C}$ is attributed to $\mathrm{C}=\mathrm{O}$ stretching vibration in the carboxylic groups. This band disappeared at higher temperature which indicates the degradation of surface functional groups. A strong band at $1581 \mathrm{~cm}^{-1}$ is ascribed to $\mathrm{C}=\mathrm{C}$ stretching variation in aromatic rings. The intensity of $\mathrm{C}=\mathrm{C}$ stretch decreased at higher temperature which is assumed due to the bond cleavage in aromatic rings. The band observed at $1424 \mathrm{~cm}^{-1}$ is ascribed to $\mathrm{C}-\mathrm{O}-\mathrm{H}$ stretching vibration in carboxylic group which shows stronger intensities at higher temperature. The bands between 1234 and $1153 \mathrm{~cm}^{-1}$ are generally ascribed to $\mathrm{C}-\mathrm{O}$ stretching vibration in phenol and alcohol groups. The bands at $883-746 \mathrm{~cm}^{-1}$ are assigned to $\mathrm{C}-\mathrm{H}$ out-of-plane bending in the aromatic rings which show lesser intensities at higher temperatures. Reducing intensity of bands between $883-$ $746 \mathrm{~cm}^{-1}$ may support the process of the bond cleavage of $\mathrm{C}=\mathrm{C}$ stretch at band $1581 \mathrm{~cm}^{-1}$ indicating the progressive elimination of hydrogen functional groups. The presences of band at $3403 \mathrm{~cm}^{-1}(\mathrm{O}-\mathrm{H}$ stretch) and between 1234 and $1153 \mathrm{~cm}^{-1}(\mathrm{O}-\mathrm{H}$ stretch) on the structures proved that the activated carbons have oxygen functional groups consisting of carboxylic, phenol or lactonic group. In general, these bands show low intensity with increasing temperatures. It assumed that the some of the surface functional groups on the surface carbon was evaporated.

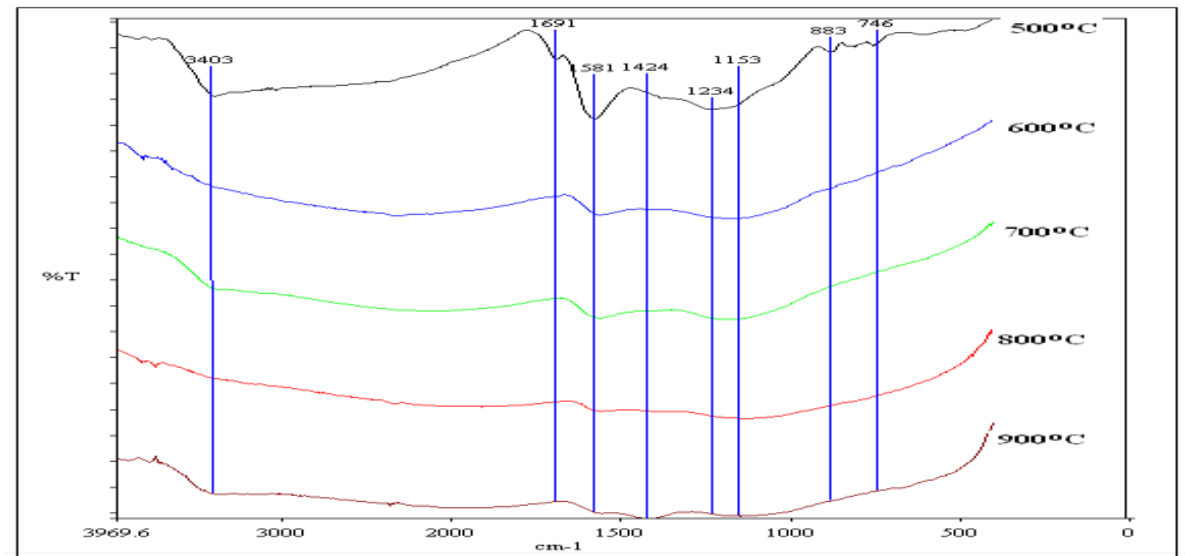

Fig. 2 FT-IR spectra of activated carbon at different activation temperatures

\subsubsection{The activated carbon after chemical treatment}

The modification surface functional groups were carried out by the chemical treatment. The activated carbon with the highest surface area (obtained at $800^{\circ} \mathrm{C}$ ) was selected for the surface modification models. As expected, modification with chemical treatment might develop the presences of oxygen and nitrogen functional group on the surface. The modification was conducted by $25 \%$ ammonia $\left(\mathrm{NH}_{3}\right), 10 \mathrm{M}$ of nitric acid $\left(\mathrm{HNO}_{3}\right)$ and $50 \%$ urea $\left(\mathrm{NH}_{2} \mathrm{CONH}_{2}\right)$. 
Fig. 3 shows the FTIR spectra of surface functional groups using ammonia, nitric acid and urea. The FT-IR spectra of nitrogen and carbon dioxide were obtained from the previous preparation using nitrogen and carbon dioxide, respectively. The result shows that some peaks on the carbon dioxide spectra were disappeared on the surface carbon. It might be due to the effect of high temperature. The presence of a band at $3422 \mathrm{~cm}^{-1}$ is assigned to $\mathrm{O}-\mathrm{H}$ stretching vibration in hydroxyl groups. This band is also strongly associated with the $\mathrm{N}-\mathrm{H}$ stretching vibration in amine and amide group which appeared at ammonia and urea modification. A weak band at $2911 \mathrm{~cm}^{-1}$ is attributed to $\mathrm{C}-\mathrm{H}$ stretching vibration of the aliphatic structures. A strong new band at $1712 \mathrm{~cm}^{-1}$ on the nitric acid treatment is assigned to $\mathrm{C}=\mathrm{O}$ stretch in carboxylate, ketones, lactones and aldehydes[21]. A band at $1568 \mathrm{~cm}^{-1}$ is generally ascribed $\mathrm{C}=\mathrm{O}$ stretching vibration in the carbonyl group as the acid treatment, and conjugated with $\mathrm{C}=\mathrm{C}$ stretching vibration in aromatic rings. This band overlaps with $\mathrm{C}=\mathrm{N}$ and $\mathrm{N}-\mathrm{H}$ stretching vibration in the pyridine and amide structure which may be found in ammonia and urea. The bands between 1393 and $1097 \mathrm{~cm}^{-1}$ are assigned to $\mathrm{C}-\mathrm{O}$ stretching vibration in phenol and alcohol groups. However, ammonia and urea modification show that the bands between 1393 and $1097 \mathrm{~cm}^{-1}$ are probably due to $\mathrm{C}-\mathrm{N}$ stretching vibration in aromatic rings and $\mathrm{N}-\mathrm{O}$ stretching vibration groups, respectively [22, 23]. The presences of band below $794 \mathrm{~cm}^{-1}$ are ascribed to $\mathrm{C}-\mathrm{H}$ in out-of-plane bending in the edges of aromatic rings or are assigned to cyclic amides. Modifications of surface functional groups with nitric acid have increased the presences of acid group. It might be caused by the removal of inorganic compounds and leaving sites on the carbon following with a chemisorbs oxygen [24]. It can be notified that increasing the intensity of the FT-IR spectra for $\mathrm{C}=\mathrm{O}$ (carboxylic group), $\mathrm{O}-\mathrm{H}$ (hydroxyl group) and $\mathrm{C}-\mathrm{O}$ (phenol group) stretching vibrations indicate the presence more oxygen functional groups on the activated carbon. Surface modifications of the activated carbon with ammonia and urea were expected to extend the surface functional group with $\mathrm{N}-\mathrm{H}$ group. Previous study reported that ammonia decomposes at high temperature with the formation of radicals such as $\mathrm{NH}_{2}, \mathrm{NH}$ and $\mathrm{H}$. These radical may react with carbon surface to form nitrogen functional groups such as $-\mathrm{NH} 2$, -CN, pyridine and pyrrolic [25]. The presence of band at $3422 \mathrm{~cm}^{-1}$ and between 1393 and $1097 \mathrm{~cm}^{-1}$ may indicate the $\mathrm{N}-\mathrm{H}$ group in form of - $\mathrm{CO}-\mathrm{NH}-$, showing the existence of the nitrogen functional groups.

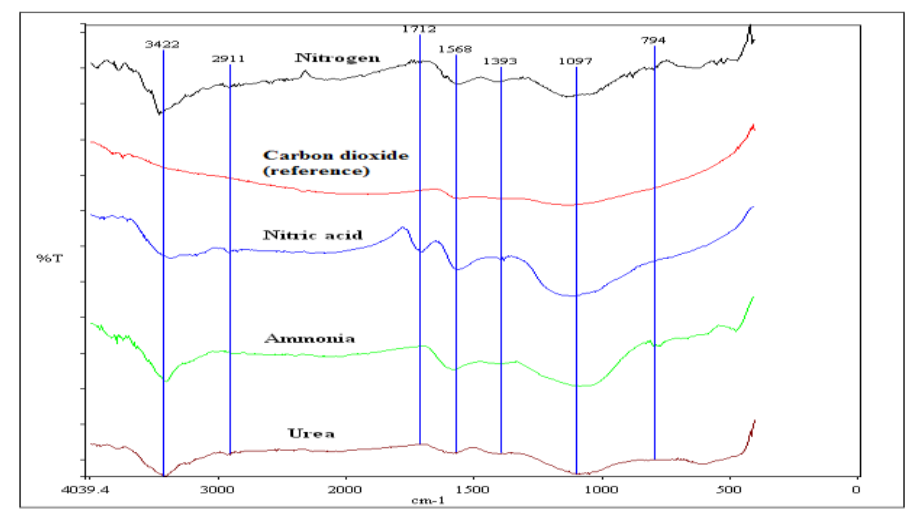

Fig. 3. The FT-IR spectra of activated carbons after chemical treatments

\subsection{Characteristics of Surface Chemistry by Boehm Titration}

Acid and basic treatments for surface modification were carried out with nitric acid, urea and ammonia as oxidizing agents. Table 4 shows the results of Boehm titration in term of total acid and basic groups. The results show that the reference of activated carbon $\mathrm{KC}$ has $0.01 \mathrm{meq} \mathrm{g}^{-1}$ of carboxylic groups which contain a very low total acid group. However, after treating by nitric acid, the results show high number of carboxylic, lactonic and phenolic groups, but non total basic groups. It indicated that introducing nitric acid to the reference activated carbons have extended the number of oxygen functional groups such as $\mathrm{O}-\mathrm{H}, \mathrm{C}=\mathrm{O}$, and $\mathrm{C}-\mathrm{OH}[26]$. These results were relevance with the FTIR spectra of activated carbon under nitric acid (Fig. 3) with appearing new peaks at bands $1712 \mathrm{~cm}^{-1}$. The activated carbon KU was also obtained an increasing the number of acid groups, carboxylic and lactonic groups, compared to activated carbon KC. The presence of total basic groups on the activated carbon $\mathrm{KC}, \mathrm{KU}$ and $\mathrm{KA}$ may be assumed due to the existing of $\mathrm{N}-\mathrm{H}$ and $\mathrm{NH}_{2}$ groups. Reaction between ammonia with activated carbon containing $\mathrm{C}-\mathrm{H}$ group on its surface leads the formation of pyrrole-like surface structure with $\mathrm{N}-\mathrm{H}$ group. In addition, ammonia may decompose at high temperature to form radicals such as $\mathrm{NH}_{2}, \mathrm{NH}$ that reacted with activated carbon to form basic functional groups $-\mathrm{NH}_{2}$ and $-\mathrm{CN}$ [7]. 
Characteristics Of Pore Structures And Surface Chemistry Of Activated

Table 4: Total acid and basic groups on surface modification of activated carbon

\begin{tabular}{|c|c|c|c|c|c|}
\hline \multirow{2}{*}{$\begin{array}{l}\text { Type of } \\
\text { sample }\end{array}$} & \multicolumn{3}{|c|}{ Acid groups, $\left(\mathrm{meq} \mathrm{g}^{-1}\right)$} & \multirow{2}{*}{$\begin{array}{l}\text { Total Acid } \\
\text { group }_{\left.\mathrm{g}^{-1}\right)}^{(\text {meq }}\end{array}$} & \multirow{2}{*}{$\begin{array}{l}\text { Total basic } \\
\operatorname{group}_{\left.\mathrm{g}^{-1}\right)}(\mathrm{meq}\end{array}$} \\
\hline & Carboxylic & Lactonic & Phenolic & & \\
\hline $\mathrm{KC}$ & 0.01 & - & - & 0.01 & 0.55 \\
\hline $\mathrm{KN}$ & 0.42 & 0.09 & 0.27 & 0.78 & - \\
\hline $\mathrm{KU}$ & 0.02 & 0.04 & - & 0.06 & 0.14 \\
\hline KA & 0.15 & - & - & 0.15 & 0.20 \\
\hline
\end{tabular}

in parenthesis the percent in comparison to the total of acid group; $\mathrm{KC}$, activated carbon prepared by $85 \% \mathrm{KOH}$ at $800^{\circ} \mathrm{C}$ under carbon dioxide (reference); $\mathrm{KN}$, reference activated carbon treated by nitric acid; KU, reference activated carbon treated by urea; KA, reference activated carbon treated by ammonia.

\subsection{Characteristics of Morphology Structure}

The morphology structure and elemental micro-analysis of the carbons were observed by the scanning electron microscope (SEM) and the energy dispersive X-ray analysis (EDX), respectively. Fig. 4 (a) and (b) display SEM micrograph and elemental composition of activated carbon prepared at activation temperature $700^{\circ} \mathrm{C}$. The external surface of the activated carbon is full of cavities with well-developed porous structure. The external surface shows a rough area having different pore diameters distributed over the surface of activated carbon. It seems that formation of cavity resulted from the removal of major components of raw materials and potassium hydroxide. The results of typical EDX elemental microanalysis of the activated carbon are carbon $(83.4 \%)$, oxygen $(9.2 \%)$ and potassium $(7.4 \%)$.
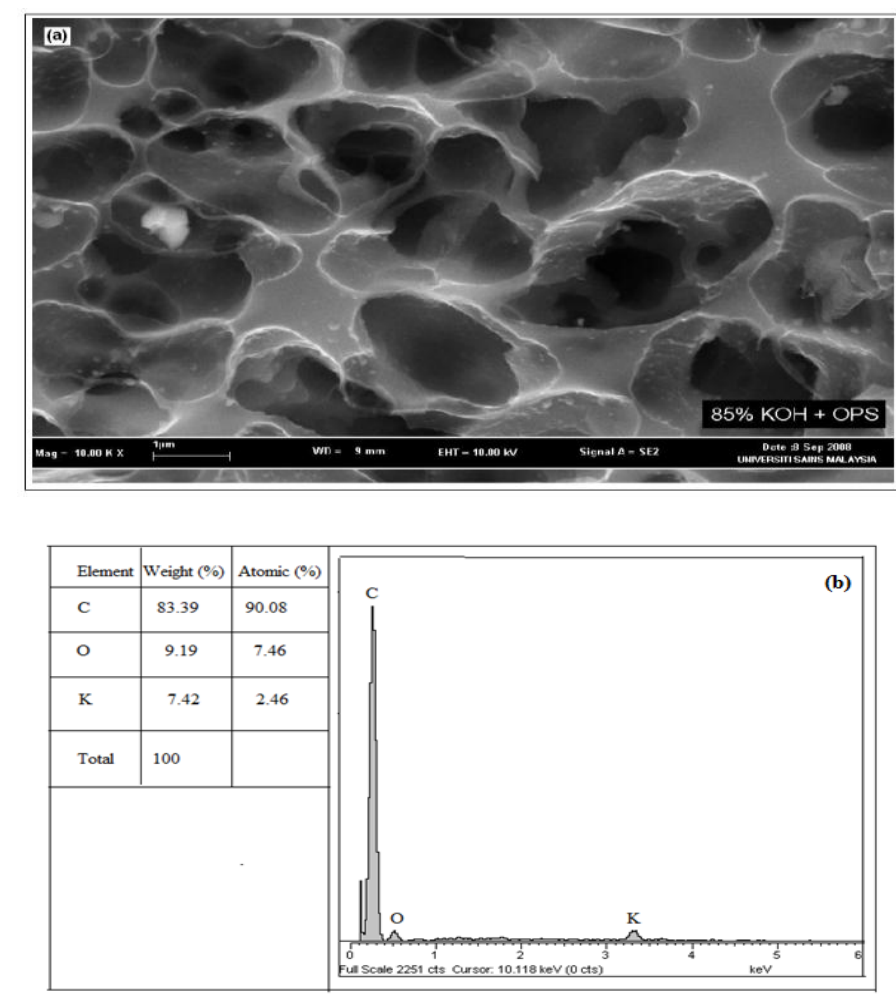

Fig. 4 Structural morphology of activated carbon: (a) external structure, (b) chemical compositions

\section{CONCLUTION}

Oil palm shell, by-product oil palm industry was used to prepare highly porous activated carbon using chemical activations potassium hydroxide as activating agents. The resulting activated carbons exhibit micropores at lower temperature and mesopores at higher temperatures. The maximum BET surface area and micropore volume were $2301 \mathrm{~m} \mathrm{~m}^{2} \mathrm{~g}^{-1}$ and $0.55 \mathrm{~cm}^{3} \mathrm{~g}^{-1}$, respectively which were obtained at temperature $800^{\circ} \mathrm{C}$. The effects of chemical treatment on the activated carbon show an improvement of the presences of surface functional groups. The results indicated that nitric acid treatment produced more oxygen surface functional 
groups on the surface of the activated carbon. In contrast, ammonia and urea treatment provided more nitrogen functional groups on the surface.

\section{Acknowledgements}

The research has been funded by School of Chemical Sciences, University Sains Malaysia (USM), Malaysia and Chemistry Department, Mathematic and Sciences faculty, Islamic University of Indonesia (UII), Indonesia.

Special acknowledgements are expressed to Assoc. Prof. DR. Ahmad Md Noor and Prof. DR. Mohd Asri bin Mohd Nawi (University Sains Malaysia) for hosting the corresponding authors in order to perform research.

\section{References}

[1] Hu, Z., Srinivasan, M.P., Mesoporous high-surface-are activated carbon. Microporous and Mesoporous Materials, 2001. 43: p. 267-275.

[2] Khalili, N.R., Campbella, M., Sandi, G., Golas, J., Production of micro- and mesoporous activated carbon from paper mill sludge I. Effect of zinc chloride activation. Carbon, 2000. 38: p. 1905-1915.

[3] Allwar, A., Ahmad, M.N., Mohd. Asri. M.N., Textural characteristics of activated carbons prepared from oil palm shells activated with $\mathrm{ZnCl}_{2}$ and pyrolysis under nitrogen and carbon dioxide. Journal of Physical Science, 2008. 19(2): p. 93-104.

[4] Biniak, S., Szymanski, G., Siedlewski, J., Swiatkowski, A., The characterization of activated carbons with oxygen and nitrogen surface groups. Carbon, 1997. 35(12): p. 1799-1810.

[5] Budinova, T., Ekinci, E., Yardim, F., Grimm, A., Björnbom, E., Minkova, V., Goranova, M., Characterization and application of activated carbon produced by H3PO4 and water vapor activation Fuel Processing Technology, 2006. 87: p. 899-905.

[6] Lastoskie, C., Gubbins, K. E., Quirke, N., Pore size distribution analysis of microporous carbons: a density Functional theory approach. J. Phys. Chem., 1993. 97: p. 4786-4796.

[7] Shen, W., Li, Z., Liu, Y., Surface Chemical Functional Groups Modification of Porous Carbon. Chemical Engineering Journal, 2008. 1: p. 27-40.

[8] Bandosz, T.J., Ania, C. O., Surface chemistry of activated carbons and its characterization, in Activated Carbon Surfaces in Environmental Remediation, T.J. Bandosz, Editor. 2006, Elsevier Ltd. All rights reserved: New York, USA. p. 159 - 229.

[9] Puziy, A.M., Poddubnaya, O. I., Martı'nez-Alonso, A., Sua'rez-Garc1'a, F., Tasco, J. M. D., Surface chemistry of phosphoruscontaining carbons of lignocellulosic origin. Carbon, 2005. 43: p. 2857-2868.

[10] Vidic, R.D., Tessner, C. H., Uranowski, L. J., Impact of surface properties of activated carbons on oxidative coupling of phenolic compounds. Carbon, 1997. 35(9): p. 1349-1359.

[11] Tseng, R.L., Physical and chemical properties and adsorption type of activated carbon prepared from plum kernels by NaOH activation. Journal of Hazardous Material, 2007.

[12] Zhang, Y., Zheng, J., Qu, X., Chen, H., Effect of granular activated carbon on degradation of methyl orange when applied in combination with high-voltage pulse discharge. Journal of Colloid and Interface Science, 2007. 316: p. 523-530.

[13] Xie, X., Goodell, B., Zhang, D., Nagle, D. C., Qian, Y., Peterson, M. L., Jellison, J., Characterization of carbons derived from cellulose and lignin and their oxidative behavior. Bioresource Technology, 2009. 100: p. 1797-18002.

[14] Guo, Y., Lua, A.C., Effect of heating temperature on the properties of chars and activated carbons prepared from oil palm stones. Journal of Thermal Analysis and Calorimetry, 2000. 60: p. 417-425.

[15] Onal, Y., Akmil-Basar, C., Sarici-Ozdemir, C., Erdogan, S., Textural development of sugar beet bagasse activated with ZnCl ${ }_{2}$. Journal of Hazardous Materials, 2007. 142(1-2): p. 138-143.

[16] Jogtoyen, M., Derbyshire, F., Activated carbon from yellow poplar and white oak by H3PO4 activation. Carbon, 1998. 36(7-8): p. 1085-1097.

[17] Allwar, A., Ahmad M,N., Mohd Asri M.N., Abdul K, Suryani, S. Toward Production of the Micro- And Mesoporous Activated Carbon From Oil Palm Shell by Chemical Activation Process with ZnCl2, H3PO4 and KOH Under Nitrogen and Carbon Dioxide Condition. in CHEMECA 2009. Burswood Entertainment Complex, Perth, Australia.

[18] Barrett, E.P., Joyner, L.G., Halenda, P.P, The determination of pore volumes and area distributions in porous substances. . J. Am. Chem. Soc, 1951. 73: p. 373-380.

[19] Boehm, H.P., Diehl, E., Heck, W. and Sappok. R, Surface Oxides of Carbon. Angew. Chemical Engineering Journal, 1964. 3: p. 669-677.

[20] Burgess, C.G.V., Everett, D. H., and Nuttall, S, Adsorption hysteresis in porous materials. Pure and Appl. Chem., 1989. 61(11): p. 1845-1854.

[21] Huang, C.C., Lin H. S., Chen, C. H., Effect of surface acidic oxides of activated carbon on adsorption of ammonia. Jounal of Hazardous Materials, 2008. 159: p. 523-527.

[22] Eichelbauma, M., Siemerb, A. B., Farrautoa, R. J.,Castaldia, M. J., The impact of urea on the performance of metal-exchanged zeolites for the selective catalytic reduction of NOx-Part II. Catalytic, FTIR, and NMR studies. Applied Catalysis B: Environmental, 2010. 97: p. 98-107.

[23] Li-Yeh, H., Teng, H., Influence of different chemical reagents on the preparation of activated cabons from bituminous coal. Fuel Processing Technology, 2000. 64: p. 155-166.

[24] Wang, S., and Zhu, Z. H, Effects of acidic treatment of activated carbons on dye adsorption. Dyes and Pigments 2007. 75: p. 306314.

[25] Przepiorski, J., Skrodzewicz, M., and Morawski, A. W, High temperature ammonia treatment of activated carbon for enhancement of $\mathrm{CO}_{2}$ adsorption. Appplied Surface Science, 2004. 225: p. 235-242.

[26] Huanga, G., Shib, J. X. and Langrishb, T. A.G, Removal of Cr(VI) from aqueous solution using activated carbon modified with nitric acid. Chemical Engineering Journal, 2009. 152: p. 434-439. 